\title{
SHORT COMMUNICATION Variations of Thin Metallic Zinc Film Resistances with Sputtering Rate
}

\author{
C. TELLIER and A. TOSSER \\ Laboratoire d'Electronique et d'Automatique, U.E.R. des Sciences et Techniques, Place Robert \\ Schuman, B.P. 4006 - 76077 LE HAVRE Cedex - FRANCE
}

(Received May 25, 1975; in final form June 26, 1975)

Variations of resistance of evaporated ${ }^{1}$ or sputtered $^{2}$ films during deposition have been studied for deposition times lower than five minutes and for resistances higher than $100 \Omega \mathrm{sq}^{-1}$. As our main objective is to study the conduction mechanisms ${ }^{3}$ in sputtered films over the thickness range from 200 to $1500 \AA$ (i.e. in the 10 to $100 \Omega \mathrm{sq}^{-1}$ sheet resistance range), we report in this note our investigations about the electrical resistance $R(T)$ of zinc films for deposition time, $T$ greater than two minutes and for four average deposition rates.

Preparation of films has been described in a previous paper; ${ }^{4}$ they are deposited by d.c. diode sputtering of a zinc target (99.9\% purity) in an atmosphere of $U$ grade argon. As broken sputtering is equivalent to continuous deposition ${ }^{4}$, sputtering was stopped every minute to measure the resistance $R$ with a multimeter. The average sputtering rate was determined from the deposition time and the film thickness measured by an optical method; ${ }^{5}$ this method is adequate for we have observed very slight anisotropic effects, ${ }^{6}$ which seem more important for higher sputtering rates $;{ }^{7}$ it varied with the intensity $I_{e}$ of the glow discharge current, the voltage $U_{e}$ remaining constant (curves 1, 2, 3 on Figure 2). Variations of the deposition rate as a function of the intensity $I_{e}$ of glow discharge current for a voltage equal to $1500 \mathrm{~V}$ are shown in Figure 1. This curve is in good agreement with the results of Laville Saint-Martin ${ }^{8}$ who established that sputtering rate $v$ is given by

$$
v=I_{e} U_{e} \exp \left\{-A U_{e}^{-1}-B U_{e}\right\}
$$

where $A, B$ are constants.

For high voltage values in the range 1000 to $1750 \mathrm{~V}$, eq. (1) may be expressed as

$$
v \propto I_{\mathrm{e}}
$$

Variations of zinc film resistance $R(T)$ versus

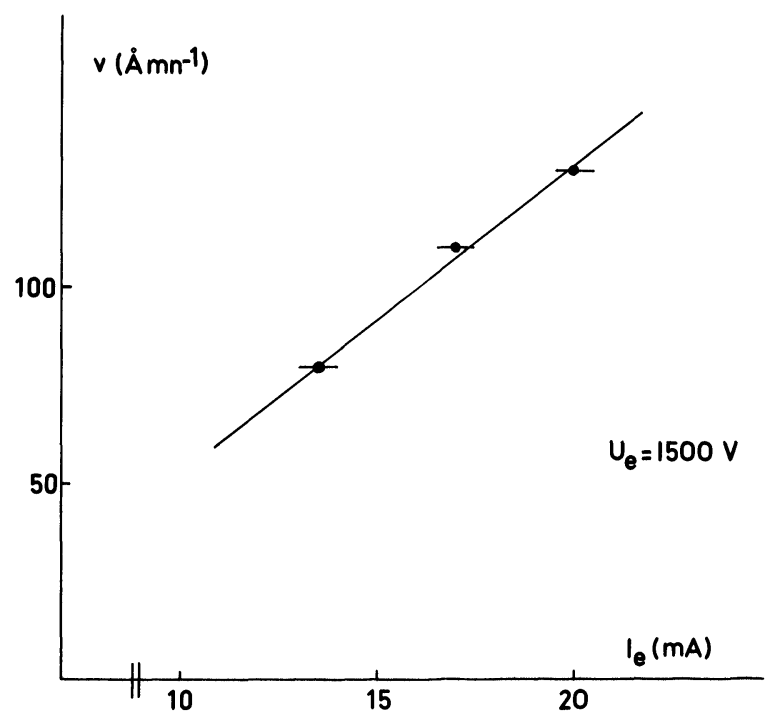

FIGURE 1 Variations of the average sputtering rate $v$ with the intensity $I_{e}$ of the glow discharge.

deposition time $T$ are plotted in Figure 2. Attempts have been made ${ }^{1,2}$ to fit these experimental variations to an empirical equation in the form

$$
R(T)=R_{\infty} \exp \frac{1}{K_{1}+K_{2} T}
$$

where $R_{\infty}$ is the limiting value of $R(T)$ when $T$ is large and $K_{1}$ and $K_{2}$ are constants.

As we have established that films thicker than $5000 \AA$ exhibit bulk properties, ${ }^{4}$ their resistance $R_{b} \approx 2.5 \Omega \mathrm{sq}^{-1}$ is assumed equal to $R_{\infty}$. Substituting for $R_{\infty}$ in Eq. 3, this yields

$$
R(T)=R_{b} \exp \frac{1}{K_{1}+K_{2} T}
$$




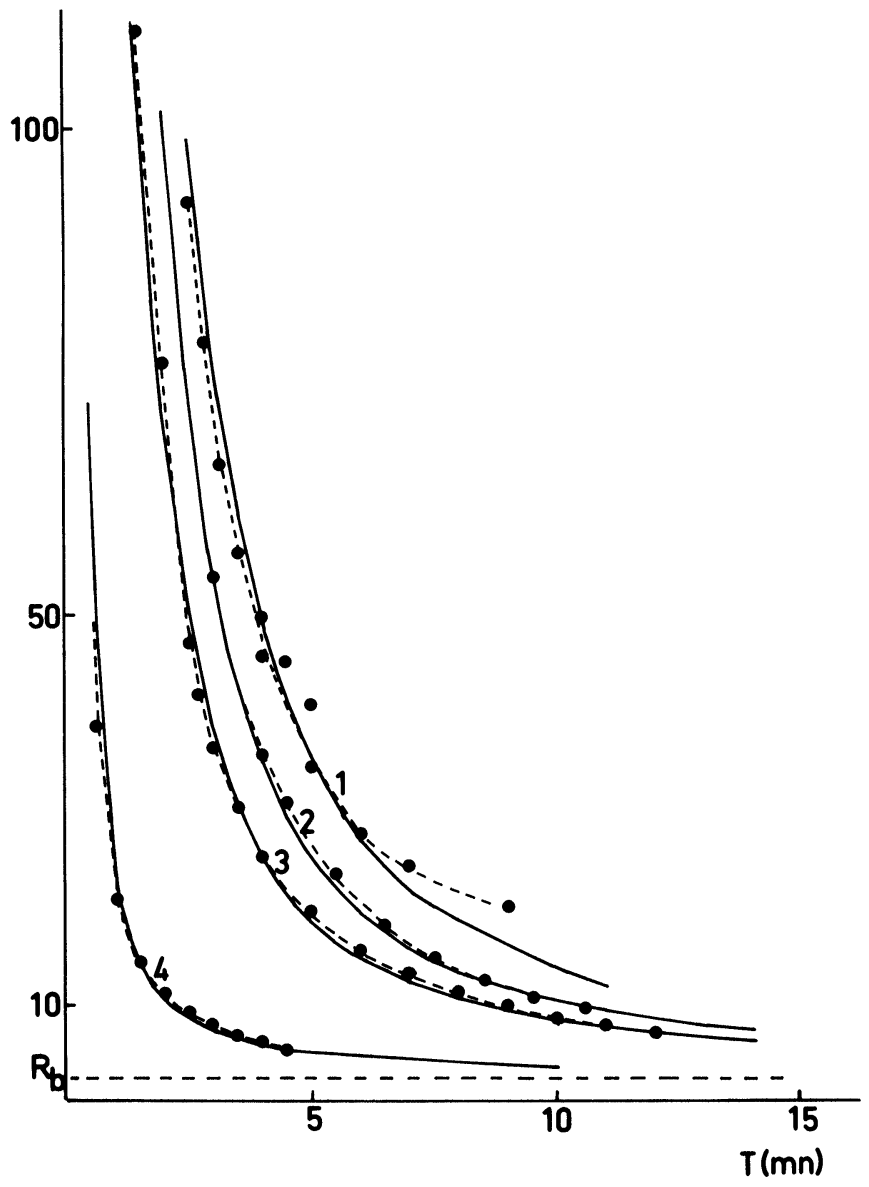

FIGURE 2 Experimental (dotted lines) and theoretical (full lines) variations of zinc film resistance $R$, with sputtering rate $v$, equal to: (1) $80 \AA \mathrm{mn}^{-1}$, (2) $110 \AA \mathrm{mn}^{-1}$, (3) $130 \AA \mathrm{mn}^{-1}$, (4) $550 \AA \mathrm{mn}^{-1}$.
$K_{1}$ and $K_{2}$ are determined by plotting $1 / \operatorname{Ln}[R(T) /$ $R_{b}$ ] versus deposition time $T$ (Figure 3 ). The slopes of the best fit straight lines determine the values of $K_{2}$, while $K_{1}$ is calculated from the intercept with the vertical axis.

From Figure 3 it can be seen that $K_{1}$ is independent of the deposition rate as indicated by Eq. 4 . Thus,

$$
K_{1} \approx 1 / \operatorname{Ln}[R o / R]
$$

where $R o$ is the substrate resistance.

However the value of $R o$ calculated from the experimental value of $K_{1}$ is low (about $6 \mathrm{k} \Omega$ ). As quasi-linear growth occurs only above the first critical thickness ${ }^{9}$ we assume that this value corresponds to a smaller thickness for which the granular structure consists of a large number of empty channels distributed throughout the film. It has been shown that the value of the resistance of such a film depends essentially on the geometrical arrangement of the sputtering chamber which remained unchanged in our experiments.

Calculations allow one to determine suitable values of $K_{2}$, leading to a good agreement between the experimental and theoretical curves (Figure 2) in the resistance range 10 to $100 \Omega \mathrm{sq}^{-1}$. A discrepancy of less than $10 \%$ is observed except for the lower sputtering rate but experimental accuracy is low in this case $(15 \%)$.

The observed slight departures from the theoretical resistance at low $R$ values occur at low sputtering rates, ${ }^{3}$ whereas considerable departures have previously been observed by Laville Saint-Martin ${ }^{7}$ for higher sputtering rate.

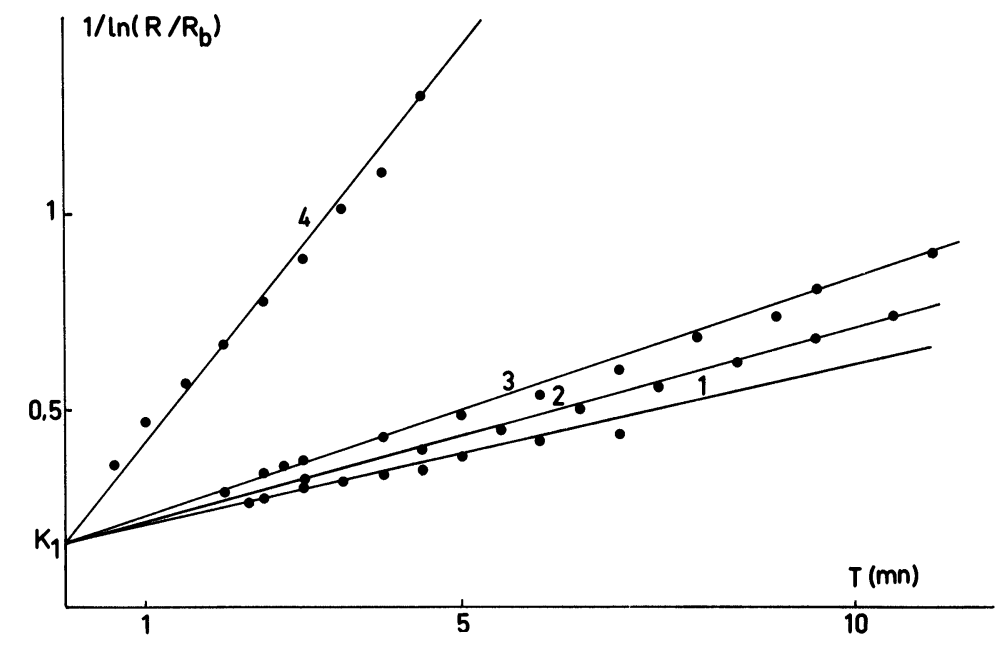

FIGURE $31 / \operatorname{Ln}[R(T) / R b]$ versus $T$ (deposition time) with sputtering rate, $v$, equal to (1) $80 \AA \mathrm{mn}^{-1}$, (2) $110 \AA \mathrm{mn}^{-1}$, (3) $130 \AA \mathrm{mn}^{-1}$, (4) $550 \AA \mathrm{mn}^{-1}$. 


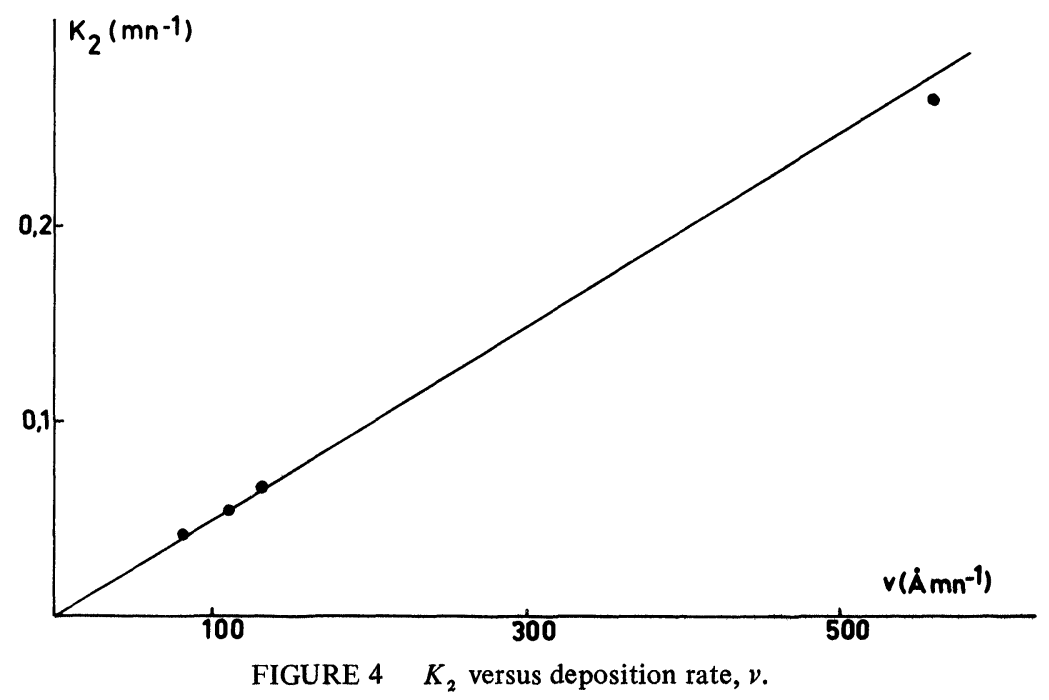

We observe (Figure 4) that the magnitude of constant $K_{2}$ differs markedly for different deposition rates. Constant $K_{2}$ has been defined as a velocity constant related to the sputtering rate $v$ and may be given approximately by

$$
K_{2} \approx \alpha \nu \quad \text { with } \quad \alpha=5.10^{-4} \AA^{-1}
$$

It may be concluded that in these experimental conditions the measured resistance fits the theoretical formulae obtained with the deposition rate as a parameter in the range $80 \AA \mathrm{mn}^{-1}$ to $600 \AA \mathrm{mn}^{-1}$; a simple way to predetermine thin film resistances is thus available.

\section{REFERENCES}

1. R. K. Jain and B. R. Marathe, Thin Solid Films, 14, 155-159 (1972).

2. T. J. Coutts, Thin Solid Films, 4, 429-443 (1969).

3. C. Tellier and A. Tosser, "Nucleation - growth of thin sputtered zinc films" Rapports sur les Couches Minces Université de Haute Normandie 1-14 (1975).

4. A. Tosser, G. Fleury and H. Murray, Thin Solid Films, 15, 259-273 (1973).

5. S. Tolansky, Surface Microtopography, Interscience, New York, 1960.

6. B. Laville Saint-Martin and G. Perny, Thin Solid Films, 4, 319-331 (1969).

7. B. Laville Saint-Martin, Thèse, Strasbourg (France), 1969.

8. G. Perny and B. Laville Saint-Martin, 1er Symposium Européen sur la Pulvérisation, Toulouse (France), Oct. 1969, 119-134.

9. B. Laville Saint-Martin, Thin Solid Films, 6, 359-377 (1970). 

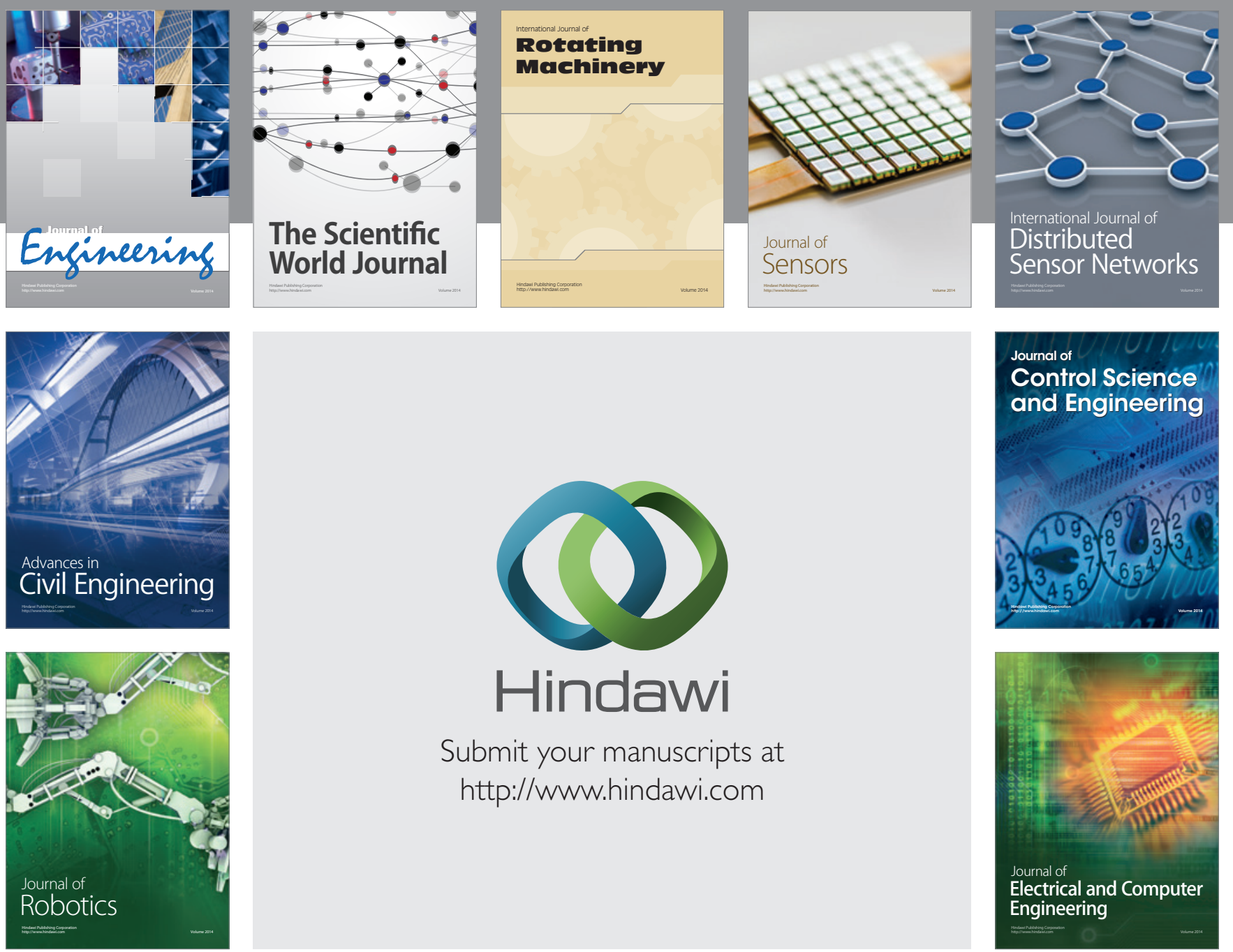

Submit your manuscripts at

http://www.hindawi.com
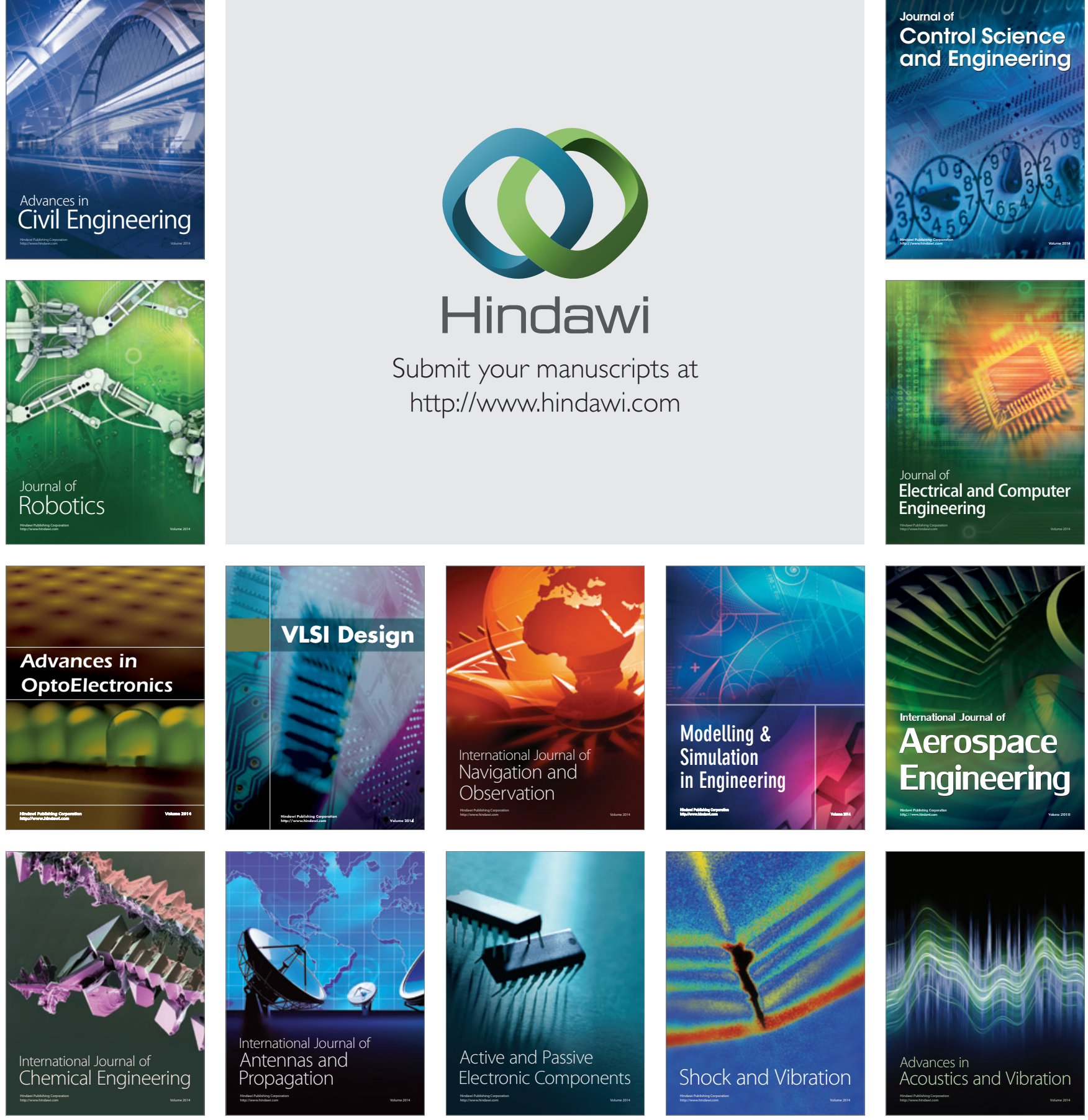